\title{
AS NOVAS CONFIGURAÇÕES DA SOBERANIA EM UMA SOCIEDADE HIPERCONECTADA
}

NEW SOVEREIGNTY CONFIGURATIONS IN A HYPERCONNECTED SOCIETY

\author{
Elias Jacob de Menezes Neto
}

\section{RESUMO}

Este artigo utiliza-se da pesquisa bibliográfica e do método dialético para abordar os fundamentos da existência do Estado Moderno e os motivos de sua crise frente aos fluxos de dados característicos da globalização. A problemática contradição entre a solidez da estrutura estatal e a liquidez do sistema atual de relações dirige-se à conclusão de que não se fazem suficientes os elementos territorializados do Estado para a proteção dos objetivos a que o mesmo se dispõe, ocorrendo, por isso, a desestruturação do Estado tradicional. Nesse sentido, opera-se a análise da transposição dos muros institucionais de poder frente à sociedade em rede.

Palavras-chave: Crise do Estado moderno. Globalização. Sociedade em rede.

\section{ABSTRACT}

This paper uses bibliographical research and dialectical method to address the existence foundations of the modern state and the reasons for its crisis compared to the data flows characteristic of globalization. There is a problematic contradiction between the solidity of state structure and the liquidity of the current system of relations. It concluded that territorialized elements of State are not enough to protect its objectives and then carried out the restructuring 
of the traditional state. Therefore, it aims to analyze the transposition of the walls of institutional power in front of the network society.

Keywords: Crisis of the modern State. Globalization. Network society.

\section{INTRODUÇÃo}

Em um mundo que se diz unificado, sem fronteiras, conectado por fluxos invisíveis, a discussão sobre a crise do Estado ${ }^{1}$ torna-se um dos principais focos de estudo sobre essa modalidade de organização política surgida na Era Moderna.

No decorrer da história, o Estado viu-se sujeito aos influxos dos diversos sistemas sociais. Isso exigiu mudanças na sua formatação, o que, por um lado, contribuiu para a sua consolidação, e, por outro, demandou adaptações e transformações. É nesse contexto em que ocorre o debate sobre as crises estatais. Por isso, a ideia de crise não está relacionada à extinção do Estado, mas ao conjunto de fenômenos que englobam as mudanças que ocorrem desde o seu surgimento.

Tendo em vista tal aspecto, este artigo analisará os fundamentos do Estado, ou seja, aquilo que permitiu o seu surgimento na Idade Moderna. Fruto dos valores da modernidade, o Estado é, por excelência, o mecanismo político institucionalizador do poder. Isso porque, por meio da monopolização da força, possibilitou-se a transferência das relações de dominação para um quadro geral e impessoal, cuja submissão exclusiva era imposta aos cidadãos.

Porém, essa mesma estrutura política vem sofrendo modificações, o que permite o questionamento a respeito das crises dos seus fundamentos. Por isso, será realizada uma análise das crises do Estado a partir do marco teórico do modelo de crises desenvolvido por Jose Luis Bolzan de Morais (2011).

Será feita, também, uma análise do modelo de crise considerado mais relevante, na linha teórica do que defendem autores como Zygmunt Bauman, Bolzan de Morais e Luigi Ferrajoli, e que está relacionado às mudanças na territorialidade proporcionadas pela globalização. Esse fenômeno acarreta na alteração do lugar de manifestação do poder e 
das fontes produtoras de direito. Isso tem, como consequência direta, a mudança na própria ideia de Estado, uma vez que, estritamente, vinculado a um território.

Diante desse complexo contexto, será visto que Saskia Sassen (2006; 2007) critica os conceitos tradicionais de globalização, pois entende que esse fenômeno envolve, além do aumento da interdependência global, a produção de estruturas espaço-temporais diferentes daquelas comumente associadas ao Estado-nação. Sob tal aspecto, será possível falar na modificação das capacidades do Estado como decorrência da globalização.

Como resultado, ainda será analisado o papel do Estado diante da nova reconfiguração mundial da soberania, decorrente tanto da modernidade líquida (Zygmunt Bauman) quanto da sociedade em rede (Manuel Castells). Nesse contexto, serão dialogados os estudos de teóricos como Georg Sorensen, Saskia Sassen e Anthony Giddens para analisar as ideias segundo as quais a soberania pode ser considerada um poder absoluto ameaçado para o Estado. Em face das contradições desta última hipótese, também se considera a ideia de que a soberania, em si, no contexto da globalização, não se perde em razão de tal avanço, mas vê redimensionadas as estruturas tradicionais do poder do Estado-nação.

\section{A CONSTRUÇÃO DO ESTADO MODERNO E OS FUNDAMENTOS DE SUA CRISE}

Antes de proceder a uma análise da crise do Estado, é imprescindível entender à qual entidade está se fazendo referência. Para tanto, deve-se situar no espaço e no tempo o surgimento dessa forma de organização do poder.

Um interessante conceito para "Estado" é dado por Anthony Giddens (1985, p. 121). Para ele, o Estado é

[...] um conjunto de formas institucionais de governança que mantêm o monopólio administrativo sobre um território com limites demarcados (fronteiras), seu domínio é sancionado pela lei e pelo controle direto dos meios de violência interna e externa ${ }^{2}$. 
Por sua vez, em outra obra, o mesmo autor informa que o Estado-nação é "a combinação de uma grande comunidade (nação) e uma forma territorial e política (Estado), criando uma entidade cultural e política, agora a 'unidade de sobrevivência' mais difundida pelo mundo" (GIDDENS, 2014, p. 5045) ${ }^{3}$.

A capacidade de organização administrativa e poder bélico para governar, efetivamente, o território somente ganhou força na Idade Moderna. Por isso, dirão inúmeros livros de teoria do Estado, essa forma de organização política surgiu a partir da superação da fragilidade do modelo político da Idade Média e do desenvolvimento de três pressupostos: território, povo e governo. Tanto é que foi somente na Idade Moderna que a palavra "Estado" passou a ganhar popularidade no sentido de "[...] máxima organização de um grupo de indivíduos sobre um território em virtude de um poder de comando [...]" (BOBBIO, 2007, p. 64).

Ampliando o debate bobbiano sobre a continuidade ou a descontinuidade do Estado, Jose Luis Bolzan de Morais e Lenio Streck (2007, p. 40) adotam a tese da descontinuidade. Para eles,

o Estado Moderno como algo novo insere-se perfeitamente em uma descontinuidade histórica, isso porque um dos maiores argumentos a confirmar tal tese é de que é o processo inexorável da concentração do poder de comando sobre um determinado território bastante vasto, que acontece através da monopolização de alguns serviços essenciais para a manutenção das ordens interna e externa, tais como a produção do direito através da lei, que, à diferença do direito consuetudinário, é uma emanação da vontade do soberano, e do aparato coativo necessário à aplicação do direito contra renitentes, bem como através do reordenamento da imposição e do recolhimento fiscal, necessário para o efetivo exercício dos poderes aumentados.

Segundo os referidos autores, três características principais serviram para diferenciar o modelo político surgido na segunda metade do século XV. A primeira delas é a autonomia e a supremacia do poder estatal. A segunda é a diferenciação entre as esferas pública (Estado) e privada (sociedade civil) ${ }^{4}$. A terceira característica diferenciadora utilizada pelos citados autores é a mudança do fundamento do poder da propriedade para o monarca, representante da soberania estatal (BOLZAN DE MORAIS; STRECK, 2007, p. 39-40). 
No mesmo sentido, Jacques Chevallier explica que o surgimento do Estado foi fruto dos valores da modernidade, em especial do culto da razão e do primado do indivíduo. Assim, o Estado é o artefato político que institucionaliza o poder, pois transfere as relações de dominação para um quadro geral e impessoal, que exige submissão exclusiva dos cidadãos. Isso porque a cidadania excluiu, na época, outras espécies de relações de poder paralelas.

Ainda, o surgimento do Estado proporcionou a monopolização da força coercitiva e a consagração da unicidade da esfera pública distinta do resto da sociedade. "Por esses motivos", diz Chevallier (2009, p. 15), "a construção do Estado aparece bastante indissociável de uma modernidade da qual ela é, por vezes, reflexo e vetor".

Um dos principais resultados das mudanças no modo como se exerce o poder é a sua despersonalização. Com sua institucionalização, o poder deixa de ser titularidade de uma casta de indivíduos e passa para o Estado, ainda que este fosse identificado com a figura do monarca. Assim, desenvolveu-se o Estado absolutista, primeira expressão do Estado moderno. Ao concentrar todo o poder nas mãos do monarca, o Estado absolutista possibilitou a transição do feudalismo para o Estado moderno, uma vez que garantiu a unidade do território, elemento central do Estado.

Em sentido contrário ao defendido pelos autores até agora referidos, Saskia Sassen (2006, p. 27) ${ }^{5}$ discorda da interpretação de que existe uma descontinuidade entre o surgimento do Estado e o período medieval anterior. Ao partir da análise dos três elementos que entende como essenciais para a sua obra (território, autoridade e direito), Sassen (2006, p. 28) conclui que "[...] a noção complexa e abstrata de autoridade legítima da soberania nacional territorial não representa uma inovação radical da ordem pós-feudal"6.

Segundo ela, o Estado moderno é apenas uma assemblage histórica que denota uma configuração específica de três elementos: território, autoridade e direito (TAR, na sigla em inglês). Essa assemblage evoluiu de tal modo que possibilitou a concentração pelo Estado da maior fatia possível dos TAR. Embora, em nenhum momento, frise-se, o Estado tenha agregado a totalidade desses três elementos, visto que sempre encontrou concorrência, os TAR acabaram por se tornar associados, exclusivamente, 
ao Estado em um movimento centrípeto que fez com que ele concentrasse a maior parte daqueles elementos.

Desse modo, uma leitura da historiografia da Baixa Idade Média que leve em conta as "capacidades medievais" 7 permite que se chegue à conclusão de que essas capacidades possibilitaram a formação do Estado nacional territorial e da sua noção de autoridade soberana.

A própria Sassen reconhece que parece paradoxal imaginar que o Estado nacional, uma entidade cuja autoridade está fundamentada na racionalidade e no território, possa ter evoluído das estruturas teológicas e desterritorializadas, que caracterizavam o medievo (a igreja, o feudalismo e o império). Todavia, argumenta que capacidades importantes criadas em um determinado período podem ser transportadas para dentro de uma lógica organizacional diametralmente oposta àquela em que elas foram criadas.

Isso ocorre porque as capacidades são multivalentes, ou seja, não são específicas de um determinado sistema, pois também se relacionam com outras capacidades. Por isso, Sassen (2006, p. 28) explica que “[...] uma capacidade pode ser orientada para novas lógicas e ser alojada em novas estruturas. Eu vejo isso acontecendo na atual era global, quando as capacidades estatais historicamente construídas para a busca de objetivos nacionais são, nos dias de hoje, reorientadas para projetos globais"8.

Ainda que, por exemplo, não existissem autoridades territorialmente exclusivas durante a Idade Média, já existiam autoridades que se pretendiam absolutas (embora não fixadas ao território), uma vez que a igreja e o império não admitiam rivais nos respectivos âmbitos. Tal fato permite perceber que já existiam projetos de uma autoridade centralizada que foram reconfigurados para a construção de uma autoridade territorialmente centralizada.

A perspectiva de Sassen é importante não apenas para a compreensão da história do Estado-nação, mas, especialmente, como ferramenta de análise das atuais transformações que essa forma de organização política vem sofrendo. Recorrer à tese da continuidade (ou, pelo menos, de uma descontinuidade parcial) significa, também, poder compreender as atuais mudanças como um processo que constitui o próprio Estado. 
A ideia de crise do Estado, portanto, passa a ter um significado diferente, pois, se for considerado que a construção do moderno deu-se a partir da mudança de objetivos de estruturas medievais, ficará mais evidente que a construção do global ocorre por meio da reorientação dos objetivos das estruturas estatais existentes. Sob tal aspecto, a própria crise é um instrumento de construção-desconstrução a partir das estruturas existentes do Estado.

A discussão sobre a crise do Estado foi iniciada, no cenário jurídico brasileiro, já na segunda metade da década de 1990, época em que o autor Jose Luis Bolzan de Morais (1996) percebeu que, mais estudadas que o próprio Estado, as suas crises parecem ser um dos principais objetos da teoria do Estado.

Conforme Bolzan de Morais (2011), a modernidade (e, em especial, sua grande invenção político-jurídica, o Estado) passa por uma fase de desconstrução de paradigmas decorrente do envelhecimento e da incompatibilidade das suas estruturas com os processos dominantes na sociedade contemporânea. Assim, o referido autor ainda divide em cinco os aspectos da crise do Estado contemporâneo: conceitual, estrutural, institucional, funcional e política.

A crise conceitual é caracterizada pelo esfacelamento da soberania como “[...] poder que é juridicamente incontrastável, pelo qual se tem a capacidade de definir e decidir acerca do conteúdo e da aplicação das normas, impondo-as coercitivamente dentro de um determinado espaço geográfico [...]" (BOLZAN DE MORAIS, 2011, p. 27). Apesar de a concorrência com outras esferas de poder não ser um novo problema estatal, a ênfase do autor concentra-se nos processos mais recentes de interferências de poderes diversos, seja no âmbito exterior, seja no interior do próprio Estado.

A crise estrutural é definida pelo enfraquecimento e flexibilização das estruturas públicas associadas aos direitos sociais. Isso ocorre em virtude: a) das dificuldades para captar recursos públicos que sejam suficientes para cobrir os gastos (aspecto fiscal da crise); b) do questionamento sobre a forma de organização do Estado social e da burocratização da resposta estatal e c) da fragmentação do fundamento filosófico do modelo do Estado social. 
A crise constitucional pode ser delimitada pelo rebaixamento da esfera pública, da legalidade e da constitucionalidade, bem como pela desvalorização do Estado de direito como sistema de limites e vínculos impostos aos poderes. Erode, assim, a esfera pública como conjunto de funções e instituições submetidas ao controle material dos direitos fundamentais, o que resulta na dilapidação, por meio da privatização e da confusão com os direitos patrimoniais, dos direitos fundamentais e, portanto, de toda a estrutura do Estado democrático de direito.

Conectada ao conceito de poderes selvagens de Luigi Ferrajoli está a crise funcional, que diz respeito à multiplicidade dos loci de poder, o que resulta no enfraquecimento do Estado como fonte central e exclusiva de poder. Essa concorrência com outros poderes ocorre tanto na esfera interna - com a transformação da tradicional tripartição dos poderes, uma vez que cada poder assume atividades dos demais -, quanto na externa - com a concorrência do Estado com outras instituições globais para fazer valer a sua legislação.

0 último viés do modelo elaborado por Bolzan de Morais é denominado crise política e de representação. Esta se caracteriza pelo esvaziamento da política, especialmente em virtude do seu distanciamento com os problemas sociais, o que ocorre através da sua fantochização. 0 sistema político representativo, como resultado da crise, demonstra-se insuficiente para lidar com as complexas transformações da sociedade contemporânea, fragilizando a democracia, já que esta acontece apenas dentro do embate político.

Em perspectiva similar, Zygmunt Bauman (1999, p. 73) fala de uma nova expropriação, nos dias de hoje, cuja vítima é o Estado. No atual paradigma, nem mesmo deve ser esperado que os Estados exerçam a maior parte das funções que, em períodos mais distantes, foram consideradas a sua raison d'être. 0 maior impacto é a capacidade de o Estado regular a sua própria economia, vez que a volatilidade do mercado global passou a ser a dominante e fez incorporar as regras do sistema econômico global às economias internas dos Estados.

Esse enfraquecimento, entretanto, não significa o fim do Estado. Para Bauman, não há contradição alguma entre o desmantelamento e a manutenção do Estado ${ }^{9}$. Conjugando Bauman e Ferrajoli, percebe-se que 
a crise do Estado é útil aos poderes selvagens, porque garante que aquele permaneça no controle, exercendo uma função que os poderes selvagens não querem assumir: a de polícia, ou seja, de garantir a ordem local. 0 Estado torna-se, assim, um fantoche dos poderes anônimos, que operam dentro das estruturas das redes criadas pela tecnologia da informação e que são imunes às fronteiras e aos limites territoriais.

Ainda que o modelo estatal viva em crise desde a sua fundação, as análises mais recentes parecem ter o fenômeno da globalização como traço comum na discussão a respeito do destino do Estado-nação, especialmente levando-se em conta que o mundo atual é caracterizado pela expansão global da tecnologia da informação e da riqueza, fenômenos que tendem a desintegrar a compreensão de fronteiras espaço-temporais.

Alguns autores apontam para a desintegração do Estado. Outros, com concepção completamente diferente, certamente mais otimista, entendem que a expansão mundial e aplicação, em grande escala, do modelo estatal seria a forma mais adequada e viável de proteger os direitos (Ferrajoli, 2011). Um terceiro grupo, formado por teóricos como Manuel Castells (2010b), percebe que o mundo está passando por um processo de transformação diversificado - mudanças econômicas, políticas, tecnológicas, institucionais e culturais - e, por isso, acredita que se está presenciando o surgimento de uma ordem global multifacetada, cuja característica principal é a sua formatação em redes de cooperação entre Estados e instituições internacionais.

Como resultado, ao invés de negar a importância do Estado ou de, pelo contrário, acreditar na possibilidade de sua aplicação em escala mundial, essa nova ordem multilateral de cogovernos requer a superação da noção de Estado da Idade Moderna, extremamente arraigada à indivisibilidade da soberania e à rigidez espaço-temporal.

A centralidade do território demonstrada pela exposição das teorias tradicionais por Bolzan de Morais e Streck (2007, p. 164), no entanto, é ignorada pelos fluxos de informações ${ }^{10}$. Em razão disso, é possível afirmar que o Estado sofre os influxos da globalização, uma vez que o seu poder diminui em virtude da expansão de forças transnacionais capazes de reduzir a capacidade de controle dos governos em diversas áreas da vida de um povo. 
Seguindo nessa direção, muitas áreas tradicionalmente associadas ao exercício da atividade estatal não podem mais ser pensadas sem a institucionalização de formas multilaterais de colaboração. Com efeito, a crise viabilizada pela globalização coloca o Estado, agora impossibilitado de gerenciar sozinho o seu próprio destino, em redes de atores públicos e privados dos mais variados tipos. Por esse motivo, é imprescindível compreender as relações entre a globalização e as forças que atuam na desconstrução do Estado.

\section{GLOBALIZAÇÃO E FORÇAS CENTRÍFUGAS DE PODER}

0 conceito de globalização tem origens na literatura do final do século XIX e do início do século XX, com as produções de Karl MarX, Saint-Simon e Halford Mackinder, quando eles remetiam à ideia de uma integração do mundo. Contudo, somente nas últimas três décadas, tornou-se extremamente comum a referência, em artigos acadêmicos, à expressão "globalização".

Embora alguns teóricos vejam a globalização como um fenômeno antigo, que vem acontecendo paulatinamente, é preciso concordar com Manuel Castells (2010a, p. 304-305). Para o mencionado autor, essas análises não levam em consideração a dimensão das mudanças impactantes das novas tecnologias na economia, na organização da produção de bens e serviços, nas comunicações e na política.

Por isso, é difícil aceitar a tese - razoavelmente difundida - segundo a qual a globalização trata-se de uma repetição dos processos que ocorreram em séculos passados, já que as novas tecnologias da informação, ao permitirem o fluxo de informações e capital em tempo real, constituem uma mudança qualitativa nas relações sociais e econômicas.

É por tal razão que, somente após a rápida expansão proporcionada pela evolução das telecomunicações, a partir do final da década de 1960, floresceram os debates a respeito da impossibilidade de se compreender esse "admirável mundo novo" utilizando os marcos teóricos dos períodos anteriores (HELD; MCGREW, 2003, p. 1). 
Esclarecida a concepção temporal de globalização adotada neste texto, é importante tentar tecer um conceito: afinal, o que se quer dizer por "globalização"? Segundo David Held (1995, p. 21), ela deve ser entendida como, pelo menos, dois fenômenos distintos. Por um lado, globalização significa que muitos aspectos da atividade política, econômica e social estão adquirindo perspectivas globais. Por outro, caracteriza um novo contexto de intensificação dos níveis de interação e interconexão entre Estados e sociedades. A novidade reside no alcance das relações sociais, expandido em virtude da tecnologia da informação, o que intensifica aquelas interconexões.

A globalização, ao invés de um processo terminado, está acontecendo neste exato instante, através da intensificação das relações sociais globais que conectam locais distantes de modo que muitos acontecimentos locais são determinados por eventos que ocorrem em lugares remotos (HABERMAS, 2001, p. 84). Sob essa visão, "a transformação local é parte da globalização tanto quanto a extensão lateral das conexões sociais através do tempo e do espaço" (GIDDENS, 2003, p. 60) ${ }^{11}$.

As teorias que versam sobre a globalização possuem três posicionamentos tradicionais: a primeira vê o Estado perdendo sua importância, ou seja, como vítima da globalização - teoria globalista; a segunda entende que pouca coisa mudou por causa da globalização e que o Estado continua atuando da mesma maneira de sempre - teoria cética; a terceira, uma posição intermediária dos posicionamentos anteriores, entende que o Estado adapta-se à globalização, garantindo sua continuação como um dos principais atores nas relações de poder contemporâneas - ou seja, teoria transnacionalista (SASSEN, 2006, p. 45) (GIDDENS, 2009, p. 137). 0 presente trabalho vincula-se, de certa forma, à corrente transnacionalista.

Simplificando, um pouco mais, essa compreensão, David Held e Anthony McGrew (2003) dividem os teóricos da globalização em dois grandes grupos: os "céticos" e os "globalistas". As discordâncias entre eles dizem respeito, primariamente, ao conceito de globalização e aos seus efeitos em cinco pontos principais: distribuição do poder; cultura; efeitos na economia; modo de aumento da desigualdade e formas de governar o mundo globalizado. A seguinte tabela ilustra bem as diferenças entre os dois grupos: 
Tabela 1 - Divisão dos teóricos da globalização em Held e McGrew

\begin{tabular}{|c|c|c|}
\hline & Sceptics & Globalists \\
\hline 1 Concepts & $\begin{array}{l}\text { Internationalization not } \\
\text { globalization } \\
\text { Regionalization }\end{array}$ & $\begin{array}{l}\text { One world, shaped by highly } \\
\text { extensive, intensive and } \\
\text { rapid flows, movements and } \\
\text { networks across regions and } \\
\text { continents. }\end{array}$ \\
\hline 2 Power & $\begin{array}{l}\text { The nation-state rules } \\
\text { Intergovernalism }\end{array}$ & $\begin{array}{l}\text { Erosion of state sovereignty, } \\
\text { autonomy and legitimacy } \\
\text { Decline of nation state } \\
\text { Rise of multilateralism }\end{array}$ \\
\hline 3 Culture & $\begin{array}{l}\text { Resurgence of nationalism } \\
\text { and national identity }\end{array}$ & $\begin{array}{l}\text { Emergence of global popular } \\
\text { culture } \\
\text { Erosion of fixed political } \\
\text { identities }\end{array}$ \\
\hline 4 Economy & $\begin{array}{l}\text { Development of regional } \\
\text { blocs } \\
\text { Tradization } \\
\text { New imperialism }\end{array}$ & $\begin{array}{l}\text { Global informational } \\
\text { capitalism } \\
\text { The transnational economy } \\
\text { A new global division of } \\
\text { labour }\end{array}$ \\
\hline 5 Inequality & $\begin{array}{l}\text { Growing North-South divide } \\
\text { Irreconcilable conflicts of } \\
\text { interest }\end{array}$ & $\begin{array}{l}\text { Growing inequality within } \\
\text { and across societies } \\
\text { Erosion of old hierarchies }\end{array}$ \\
\hline 6 Order & $\begin{array}{l}\text { International society of states } \\
\text { Political conflict between } \\
\text { states inevitably persists } \\
\text { International governance } \\
\text { and geopolitics } \\
\text { Primacy of ethically bounded } \\
\text { community }\end{array}$ & $\begin{array}{l}\text { Multilayered global } \\
\text { governance } \\
\text { Global civil society } \\
\text { Global polity } \\
\text { Cosmopolitan orientations }\end{array}$ \\
\hline
\end{tabular}

Fonte: HELD; MCGREW, 2003, p. 38.

Embora divergentes, existem pontos que são comuns às duas correntes. Todas elas, por exemplo, entendem que o aumento da interconexão econômica, cultural e política das diferentes regiões do globo modifica as tradicionais hierarquias e gera novas desigualdades no que diz respeito à distribuição de poder, riqueza e conhecimento. 
Além disso, todas concordam com o fato de que a proliferação de conflitos que ultrapassam as tradicionais fronteiras nacionais, como é o caso do fluxo global de dados, coloca em questão o problema de como o Estado pode atuar na proteção dos direitos. Tais problemas requerem novas formas de pensar a produção de um direito que seja capaz de, efetivamente, proteger os indivíduos e proporcionar a accountability típica dos regimes democráticos.

Tal contexto, ainda para David Held, coloca em risco o modelo de Estado que se conhece, ainda que não o aniquile. Isso porque entram, no jogo do poder, atores não sujeitos às tradicionais regras de democracia e accountability. Assim, sugere o autor, a globalização exige a ressignificação de conceitos como poder, legitimidade politica e autoridade, separando-os das associações tradicionais com um território fixo. Isso, contudo, requer a criação de um suporte internacional capaz de lidar com o que Held denomina direito cosmopolita, que, para ele, é a pedra angular para a sobrevivência dos regimes nacionais democráticos no mundo contemporâneo ${ }^{12}$.

De modo similar, Zygmunt Bauman (2001, p. 220) tem uma visão bastante sombria sobre os efeitos da globalização no Estado. Para ele, o interesse das multinacionais é a existência de um mundo sem Estados, ou, pelo menos, com Estados muito pequenos. Com isso, a soberania estatal seria desacreditada e removida do direito internacional, o que permite a substituição do "mundo de nações" por uma ordem supranacional.

0 referido autor entende que a globalização e, especialmente, a anulação tecnológica das distâncias serviram para polarizar, ainda mais, os seres humanos, já que esses fenômenos criaram duas categorias distintas de pessoas: de um lado, aqueles inseridos nas novas tecnologias, ou seja, emancipados dos territórios; de outro, os indivíduos excluídos que, incapazes de superar a "velocidade de escape"13 da órbita do território, acabam sendo nele confinados.

A desvalorização do espaço físico, proporcionada pela globalização - e pela tecnologia da informação -, para Bauman (1999, p. 25),

[...] assegura para alguns a liberdade face à criação de significado, mas para outros pressagia a falta de significado. Alguns podem agora mover-se para 
fora da localidade - qualquer localidade - quando quiserem. Outros observam, impotentes, a única localidade que habitam movendo-se sob seus pés.

O viés positivo da globalização, nesse aspecto, só pode ser sentido por essa elite inserida no ciberespaço. Embora a materialidade do corpo seja irrelevante nesse ciberespaço, ele gera efeitos muito relevantes para os corpos. Por isso, Bauman acredita - corretamente - que a desterritorialização e a superterritorialização são dois lados da mesma moeda.

Embora sejam divididos, de modo geral, pelo nível de pessimismo ou otimismo, Bauman, Held e McGrew aproximam-se mais daquele grupo que, na tabela anterior, foi denominado "globalista". Todos eles compartilham a ideia de um mundo unificado, o que resulta na erosão do Estado nacional, suplantado pelo multilateralismo na ordem global. O globalismo, para Held e McGrew (2003, p. 39),

[...] ilumina importantes transformações que estão acontecendo na organização espacial do poder - as mudanças da comunicação, a difusão e aceleramento das mudanças técnicas, a proliferação do desenvolvimento econômico capitalista etc. - ainda que sua compreensão desses temas, às vezes, exagere sua magnitude e impacto ${ }^{14}$.

No entanto, esse posicionamento não leva em conta um dado importante: a globalização e o Estado nacional não são mutuamente excludentes. 0 Estado não parece ser o grande ator do mundo globalizado, como querem os "céticos"; tampouco está caminhando para o seu fim, como querem os globalistas. 0 que parece ocorrer é uma reorganização, com a inserção de novos e poderosos players que concorrem com o Estado no mundo globalizado.

Por isso, a noção de "capacidades" trabalhada por Saskia Sassen (2006) é de vital importância para compreender como o Estado, apesar de ser modificado em virtude da globalização, continua sendo um importante ator na complexa rede de poderes mundiais, o que será visto no próximo item. 


\section{A MODIFICAÇÃO DAS CAPACIDADES DO ESTADO}

Ao criticar os conceitos mais comuns de globalização, Saskia Sassen (2007, p. 3) (2006, p. 23) afirma que esse fenômeno vai além da tradicional definição como aumento da interdependência, englobando, também, a produção de estruturas espaço-temporais que são distintas daquelas tradicionalmente erigidas pelo Estado-nação.

Por essa razão, a explicação de Held sobre o surgimento de instituições globais parece contar apenas metade da história. Isso porque a análise de Sassen pressupõe a existência de dois "níveis" de dinâmicas que regem a globalização. 0 primeiro diz respeito ao mesmo nível no qual trabalha Held, ou seja, na formação de instituições e processos explicitamente globais, como é o caso das organizações internacionais e do novo cosmopolitismo.

O segundo nível, no entanto, é mais profundo. Trata-se de processos que, embora não sejam aparentemente globais, são parte da globalização. De acordo com a autora (SASSEN, 2006, p. 3),

esses processos ocorrem nas profundezas dos domínios territoriais e institucionais que foram largamente construídos em termos nacionais na maior parte do mundo. 0 que torna estes processos parte da globalização, embora eles estejam localizados na esfera nacional (ou subnacional), é o fato de eles serem orientados em direção a propósitos e sistemas globais. Tais processos são redes e formações multilocalizadas e transfronteiriças, podendo incluir ordens normativas; elas conectam processos, instituições e atores subnacionais ou "nacionais", mas não através do sistema formal interestatal. Exemplos disso são as redes transfronteiriças de ativistas engajados em lutas que, embora locais, possuem objetivos implícita ou explicitamente globais, como é o caso dos direitos humanos e das organizações ambientalistas; aspectos particulares do trabalho dos Estados como, por exemplo, certas políticas monetárias e fiscais essenciais para a constituição dos mercados globais e que estão sendo implementadas em um número de países cada vez maior; o uso dos instrumentos internacionais [de proteção dos] direitos humanos em cortes nacionais; e as formas não cosmopolitas de política global que permanecem profundamente vinculadas ou concentradas com problemas e lutas localizadas ${ }^{15}$. 
Assim, para a autora, os estudiosos, comumente, caem em uma espécie de "armadilha da endogenia" quando tentam estudar um objeto - a globalização -, centrando-se apenas nas qualidades deste objeto - as instituições e os processos globais. Não é por outra razão que a maior parte da literatura sobre globalização afirma somente que ela representa o aumento da interdependência entre nações e players globais, com o consequente declínio do Estado-nação ou a necessidade de ele se modificar caso queira sobreviver, como afirma Held (1995, p. 22).

Sassen critica a ideia de que essa nova fase globalizadora elimina ou enfraquece aquilo que fez o Estado nacional forte. Trata-se, para a autora, de uma mudança de configuração das capacidades associadas ao Estado. Um claro exemplo dado por ela é o Estado de direito (rule of law), pois

[...] o "Estado de direito" é uma capacidade que foi essencial para o fortalecimento da autoridade estatal nacional na instituição do protecionismo econômico nacional. No entanto, hoje essa capacidade também é essencial para o desenvolvimento de uma economia global no intuito de abrir as economias nacionais. Ela é suficientemente desenvolvida a ponto de poder operar no contexto do protecionismo das economias nacionais e também tornar-se pedra angular para o sucesso da desregulamentação e da privatização neoliberal - que, em alguma medida, são opostas ao protecionismo. Mas isso só pode ocorrer através do realojamento [dessa capacidade] em uma nova lógica organizacional (SASSEN, 2006, p. 13-14) ${ }^{16}$.

A literatura, normalmente, chega a essa conclusão de eliminação do Estado porque estuda apenas a modificação óbvia da assemblage composta por território, autoridade e direito proporcionada pela globalização. No entanto, costuma-se esquecer de que elementos importantes do "global" estão presentes dentro da estrutura do Estado nacional.

Em síntese, Sassen afirma que todas as "novidades" que aparecem na literatura sobre globalização têm alguma conexão e interdependência com as estruturas da modernidade associadas ao Estado-nação. Essas conexões do "novo" com o "antigo" tendem a ser tão profundamente enraizadas que, frequentemente, são ignoradas. Nas palavras de Sassen, “o novo é mais bagunçado, mais condicionado e com mais antigas linhagens do que sugerem as grandes instituições e capacidades globais" ${ }^{17}$. 
Seguindo esse raciocínio, o caso de Edward Snowden ${ }^{18}$ simboliza a reconfiguração de capacidades tradicionais. Mutatis mutandis, os instrumentos típicos da rigidez do Estado-nação (lei) e da sua relação com outros Estados (acordos internacionais) foram utilizados para permitir a coleta de dados em massa pelos EUA e seus parceiros, tarefa que incluiu, especialmente, grandes empresas de tecnologia.

Somente através do uso de estruturas estatais fortes, foi possível estabelecer um regime de coleta massiva de dados no mundo inteiro, fenômeno que é notoriamente desterritorializado. Nesse caso, o global (ou seja, o desenvolvimento da coleta massiva de dados por multinacionais e nações diversas) não poderia ter acontecido sem o uso do local (um aparato estatal incrivelmente desenvolvido e bem-estabelecido). Isso fica nítido em virtude de uma única potência mundial - os EUA - ser capaz de estabelecer os critérios de funcionamento da tecnologia utilizada em todo o globo.

Aqui, deve ser aplicada a mesma tese de Sassen sobre o debate continuidade/descontinuidade ${ }^{19}$, ou seja, de que elementos específicos do território, da autoridade do direito estão sendo reorganizados em novas configurações globais. Sob esse aspecto, é possível afirmar que

[...] a realocação [dessas capacidades] nas lógicas organizacionais, desnacionalizadora e global não apenas reorienta essas capacidades para objetivos diferentes daqueles que elas eram orientadas, mas também reconstitui a construção do público e do privado, bem como dos limites entre esses domínios (SASSEN, 2006, p. 28) ${ }^{20}$.

Ainda, sobre as análises tradicionais da globalização, é comum acreditar que o atual surgimento de múltiplos poderes não locais e privados guarda semelhança com o feudalismo. Não se trata de um retorno ao feudalismo, como querem alguns, pois a única semelhança entre o período feudal e os dias de hoje, entretanto, diz respeito à mudança dos objetivos de algumas capacidades, ou seja, assim como a construção do moderno deu-se a partir da reorientação (e não da destruição) das estruturas medievais.

Michael Mann (2003) possui uma visão um tanto similar à de Saskia Sassen no sentido de que a globalização não significa o fim do Estado. 
Embora reconheça que existe um processo de interconexão global, Mann entende que as instituições estatais continuam a ter importância no atual cenário mundial, especialmente na criação de condições de vida em sociedade e na regulação da vida social.

Existem cinco redes de interação social no mundo contemporâneo: local, nacional, internacional, transnacional e global. Dessas, as redes nacional e internacional são primariamente organizadas ao redor de Estados nacionais; por isso, para analisar a possibilidade de fim do Estado, deve-se verificar até que ponto as redes transnacional e global independem das redes protagonizadas pelo Estado.

Os entusiastas da globalização, dirá Mann (2003, p. 145), tendem a superestimar a força que o Estado nacional teve no passado e o seu atual declínio. Além disso, esquecem que a pluralidade de Estados inviabiliza falar em um processo unificado de extinção do Estado nacional, uma vez que é impossível afirmar que a fragilização do Estado ocorre da mesma forma, por exemplo, nos Estados Unidos da América e em Burquina Faso.

A globalização, portanto, não pode ser vista como um fenômeno de desconstrução do Estado-nação, como afirmam muitos teóricos. Não é a totalidade do Estado que está sendo desnacionalizada, mas apenas alguns dos seus elementos específicos. Além disso, a valência de uma capacidade determinada somente surge dentro da lógica na qual ela está inserida, de modo que é um equívoco colocar o global em rota de colisão com o local.

Sob essa ótica, a análise dos tipping points, feita por Sassen, permite concluir que o surgimento de uma nova ordem global não tem, como resultado automático ou óbvio, o fim da ordem anterior. Por outro lado, isso não quer dizer que o Estado permanece inalterado aos influxos da globalização, sem mudar suas estruturas.

Embora as redes global e transnacional estejam sendo fortalecidas pela globalização, isso não significa o fim das redes nacional e internacional. As interações humanas ocorrem de forma muito mais complexa que o possibilitado pelo raciocínio disjuntivo. Assim, é preferível falar de redes que se sobrepõem e, portanto, é incabível falar que a globalização leva ao fim do Estado. 


\section{O ESTADO E A NOVA CONFIGURAÇÃO DA SOBERANIA}

A globalização da economia gera, sem dúvida, importantes mudanças na organização territorial da economia e do poder. Essa reorganização do poder modifica os pressupostos de exclusividade territorial do Estado-nação, ou seja, altera a compreensão acerca da soberania, que foi construída através da ideia de exclusividade territorial mutuamente excludente.

Nessa perspectiva, é a definição dada por Jose Luis Bolzan de Morais (2011, p. 27). Para o autor, a soberania é

[...] um poder que é juridicamente incontrastável, pelo qual se tem a capacidade de definir e decidir acerca do conteúdo e da aplicação das normas, impondo-as coercitivamente dentro de um determinado espaço geográfico, bem como fazer frente a eventuais injunções externas. Ela é, assim, tradicionalmente tida como una, indivisível, inalienável e imprescritível. Neste viés, pode-se dizer que a soberania moderna é aquela típica do Estado-Nação. Aquela caracterizada por uma estrutura de poder centralizado e que exerce o monopólio da força e da política - legislativa, executiva e jurisdicional sobre um determinado território - como um espaço geográfico delimitado por suas fronteiras - e a população - como um conjunto de indivíduos que é reconhecido como cidadão/nacional - que o habita.

Soberania e território continuam a ser importantes aspectos no mundo globalizado, embora eles estejam sendo deslocados para outras arenas institucionais fora dos moldes tradicionais do Estado-nação e do território nacional. Segundo Saskia Sassen (1996), a soberania está sendo descentralizada, e o território, parcialmente desnacionalizado. A desnacionalização do território ocorre como efeito das práticas de empresas transnacionais e do surgimento de um regime jurídico paralelo, ainda que incipiente.

Para Sassen, ao invés de ser destruída, a soberania está sendo transformada pela globalização. Há uma proliferação dos loci onde ela é exercida, processo que ocorreu nos últimos anos através da reconfiguração da intersecção entre soberania e território. Assim, afirma a referida autora (SASSEN, 2006, p. 21): 
A atual fase da globalização consiste, pelo menos parcialmente, em sistemas globais evoluindo das capacidades que constituíram o Estado territorial soberano e o sistema interestatal. Em outras palavras, o Estado territorial soberano, com sua rigidez e exclusividade territorial, representa um conjunto de capacidades que, eventualmente, permitiram a formação ou evolução de sistemas globais particulares - eles próprios uma condição parcial - que não requerem territorialidade nem exclusividade ${ }^{21}$.

Essa não é, contudo, a perspectiva mais amplamente difundida na literatura sobre o tema. Na maioria dos casos, entende-se que o Estado-nação está perdendo sua soberania, especialmente, porque esse conceito, desde Bodin, exige a exclusividade do poder de decisão. Nessa visão, Manuel Castells entende que a capacidade de reação do Estado está fatalmente comprometida, especialmente em virtude da globalização das atividades econômicas, do crime e das tecnologias da informação (CASTELLS, 2010a, p. 288).

A globalização, indiscutivelmente viabilizada pela tecnologia de informação, possibilita, na perspectiva visivelmente mais pessimista de Bauman (1999, p. 63), que o poder mova-se em uma velocidade tal que ele esteja sempre à frente do - lento, porque territorial - Estado-nação. Movendo-se na velocidade da luz nas fibras ópticas e sinais de micro-ondas, o poder passa a se tornar livre das restrições relacionadas aos territórios.

É por isso que Bauman afirma que o Estado está sofrendo um processo de definhamento, rumo a um fim catastrófico, com o consequente surgimento de uma "nova desordem mundial". Afinal, se "ordem", para o referido autor, significa "estar no controle", situação tradicionalmente associada à modernidade, a "desordem" resulta do inverso, ou seja, do completo caos de poderes ao qual está submetido o Estado.

Como parte desse caos, o Estado acabou perdendo o que, para Bauman, é uma das suas características mais importantes: a capacidade de transformar contingência em determinação, ou seja, diminuir a desordem. Isso significa que "os três pés do 'tripé da soberania' foram quebrados sem esperança de conserto. A autossuficiência militar, econômica e cultural do Estado - de qualquer Estado -, sua própria autossustentação, deixou de ser uma perspectiva viável" (BAUMAN, 1999, p. 73). 
Esse fenômeno, para Bauman, ocorre como uma resposta do Estado. Em troca da manutenção da sua capacidade de policiar a lei e a ordem, o Estado passou a fazer alianças e entregar, voluntariamente, pedaços, cada vez maiores, da sua soberania. Aqui, embora não concordem no que diz respeito às consequências da perda da soberania, é aplicável também a perspectiva de Sassen a respeito da não vitimização do Estado, pois, segundo Bauman, os Estados não foram forçados a abrir mão da sua soberania, mas assim procederam de modo voluntário, já que eles

[...] imploravam que sua soberania lhes fosse tirada e dissolvida em formações supra-estatais. [...] A nova oportunidade representada pelo desprezo das duras e exigentes condições do Estado foi usada por dezenas de "novas nações" em uma corrida para instalar seus próprios escritórios no já superlotado edifício da $\mathrm{ONU}$, não projetado para acomodar um número tão grande de "iguais". [...] Paradoxalmente, foi a morte da soberania do Estado, não o seu triunfo, que tornou tão popular a idéia da condição estatal (BAUMAN, 1999, p. 72, grifo do autor).

De maneira similar à de Bauman, Manuel Castells (2010a, p. 304) entende que a soberania do Estado-nação é decisivamente minada pela globalização de diversos processos e atividades na sociedade contemporânea, como ocorre com o fluxo de capitais, produção econômica, crime etc.

Por isso, é possível afirmar que a globalização é, em parte, endógena do próprio Estado-nação, tendo evoluído a partir das suas capacidades. Porém, é difícil, para a teoria do Estado tradicional, afirmar, como pretende Sassen, que o Estado ainda retém soberania (moderna) quando esta é compartilhada. Para uma teoria mais conservadora, essa nova distribuição de poder pode ser considerada outra coisa: uma nova configuração mundial, com uma nova forma desterritorializada do exercício do poder, mas não soberania no sentido tradicional. A soberania, tradicionalmente, tem um sentido sólido, indivisível, uno, típico da modernidade do hardware (BAUMAN, 2001); as novas configurações desterritorializadas de poder possuem fluidez típicas da modernidade do software.

Para escapar, um pouco, dessa ideia de soberania tradicional, Michael Hardt e Anthony Negri (2003, p. 116) entendem que ocorreu o declínio da 
soberania do Estado-nação, mas não da soberania em si. Para os referidos autores, a globalização continua sustentando a existência de atores capazes de exercer o controle político, as funções estatais e os mecanismos regulatórios, ainda que esses papéis não sejam atribuídos ao Estado.

No entanto, os autores não afirmam que os Estados compartilham a soberania com outras instituições. De acordo com eles, a própria soberania tomou uma nova configuração ao ser composta de forma global, exercida por Estados e instituições supranacionais, regidos por uma única regra. Essa soberania globalizada recebe um novo nome: "Império".

A passagem para o Império, por sua própria natureza, somente ocorre com o declínio da soberania da modernidade. Ao contrário do modelo anterior, o Império não necessita de um centro territorial que emana poder, tampouco depende de estruturas territorializadas. Assim, o Império

é um aparato de governo decentralizado e desterritorializador que progressivamente incorpora todo o domínio global com as suas fronteiras abertas e expansíveis. 0 Império gerencia identidades híbridas, hierarquias flexíveis e trocas plurais através de redes de comando moduladas (HARDT; NEGRI, 2003, p. 117) 22 .

Por tal razão, a proposta de Sassen é interessante para compreender que o aparato do Estado-nação, ao invés de ser destruído pela globalização, torna-se ele próprio o suporte para o desenvolvimento da nova ordem, afinal, "uma nova ordem não é uma invenção ab novo, e ela não necessariamente se anuncia como nova, como uma estranheza radical como ficção científica ou relato futurista" (SASSEN, 2006, p. 11) ${ }^{23}$.

De modo absolutamente diverso, Georg Sorensen (2010) entende que o núcleo da soberania permanece intacto mesmo diante das mudanças proporcionadas pela globalização. Segundo ele, existem três aspectos que justificam a sua hipótese e que devem ser analisados: 1) o núcleo jurídico da soberania, que ele entende ser a independência constitucional; 2) as normas que regulam essa soberania, ou seja, a reciprocidade e a não intervenção e 3) a realidade material do Estado, ou seja, sua capacidade real para agir e controlar sua economia e instituições político-administrativas. 
0 autor apresenta o contraponto no que chama "debate sobre o fim da soberania", contestando aqueles que, para ele, assumem uma postura "apocalíptica" do fim do Estado e aqueles que entendem que a soberania e o Estado estão mais fortalecidos do que nunca. Aponta cinco fatores principais que impulsionam o debate:

1. As transmissões de dados informatizados, as emissões de rádio, a detecção remota por satélite e as chamadas por telefones celulares não se restringem nos controles de fronteira. Ademais, essas comunicações ocorrem: (a) a velocidades que fazem difícil que a vigilância dos Estados as detecte de antemão; e (b) em quantidades que nenhum Estado pode perseguir, ainda que aumente as suas capacidades.

2. Os meios eletrônicos de massas também supõem uma perda do domínio do Estado sobre a construção da língua e da educação.

3. Um estado não pode exercer autoridade plena sobre associações transfronteiriças e empresas globais.

4. Um Estado não pode assegurar com êxito o domínio supremo e exclusivo sobre os fluxos financeiros globais que atravessam a sua jurisdição.

5. As condições ecológicas mundiais, como a diminuição da camada de ozônio e da diversidade biológica também minaram os requisitos materiais da soberania (SORENSEN, 2010, p. 129) ${ }^{24}$.

Sorensen, ao negar que esses fatores são capazes de remover a soberania do Estado, aponta que as propostas a respeito do "fim da soberania" estariam fundamentadas em um erro de categoria. De acordo com ele, a soberania deve ser entendida como uma instituição jurídica que compreende a independência constitucional e das suas normas reguladoras.

Logo, por entender que tais características permanecem impávidas aos cinco problemas que elenca, Sorensen acredita que os defensores do esvaziamento da soberania, em virtude da diminuição das oportunidades de controle por parte do Estado, estão, na verdade, confundindo a realidade material do Estado - que o autor entende sofrer mudanças com a instituição jurídica da soberania - que, para Sorensen, permanece inalterada.

A fim de defender seu ponto de vista, Sorensen afirma que a história do modelo estatal é mal interpretada, uma vez que as interferências sem- 
pre existiram nos assuntos do Estado, o qual nunca foi capaz de regular, completamente, os fluxos nas suas fronteiras.

Além disso, argumenta que a força do Estado-nação resta evidente em virtude da multiplicação do número de Estados soberanos a partir dos anos de 1945, sem competidores que coloquem, na opinião dele, essa primazia estatal em risco ${ }^{25}$. Esse, contudo, não é argumento suficiente, pois, conforme explicitado anteriormente, o enfraquecimento do Estado e a proliferação de Estados débeis não são eventos excludentes.

Por conseguinte, ainda que o "jogo moderno" e o "novo jogo" sejam diferentes, Sorensen acredita que a independência constitucional do Estado permanece intacta. Esse posicionamento, contudo, demonstra-se descabido, especialmente se for considerado a partir do problema da globalização e dos fluxos globais de dados. Ao contrário do que afirma Sorensen, quando fala da liberdade dos países europeus de simplesmente saírem da União Europeia, os Estados não estão nada livres para decidir se participam ou não dos fluxos globais de dados. Veja-se, por exemplo, o caso nacional em que, vulnerável à interferência da coleta de dados por parte da NSA, o Brasil não foi capaz de tomar nenhuma medida para alterar a situação ${ }^{26}$.

Parte dessa falta de compreensão talvez esteja relacionada ao fato de que Sorensen utiliza bibliografia das décadas de 1960 e 1980 para tentar capturar as mudanças propiciadas pela tecnologia da informação, que iniciou seu crescimento exponencial somente a partir do final da década de 1980.

As limitações da territorialidade, as transformações da soberania e a desnacionalização são características essenciais da globalização. Tais transformações são tão importantes que Jose Luis Bolzan de Morais (2011, p. 28) afirma que "falar em soberania, nos dias atuais, como um poder irrestrito, muito embora seus limites jurídicos, parece mais um saudosismo do que uma avaliação lúcida dos vínculos que a circunscrevem".

Muitos dos processos globais, porém, ainda dependem, frequentemente, da entrada no âmbito do Estado-nação para serem operacionalizados. Trata-se de um fenômeno complexo, que resiste à simplicidade das explicações duais e que requer que sejam decifradas as "[...] profundas mudanças estruturais que subjazem às continuidades superficiais e, 
alternativamente, às profundas continuidades estruturais que subjazem às descontinuidades superficiais" (SASSEN, 2006, p. 12) 27.

Em síntese: o Estado-nação é muito pequeno para lidar com os problemas globais relacionados aos fluxos globais de dados, mas muito grande para resolver os problemas dos indivíduos. Apesar da contradição simbolizada pelo poder militar dos EUA, a liquidez, cada vez maior, do mundo aponta para um processo de diminuição sistemática da soberania e do poder do Estado-nação como forma de manter sua longevidade.

Resta claro que, ao contrário do que afirma Sorensen, é desconstruída a ideia de soberania como algo absoluto. Até mesmo na Era Moderna, a soberania dos Estados "no papel" era muito maior que a realidade. A história dos últimos séculos, para Anthony Giddens (2003, p. 61), não foi uma história de gradual perda de soberania do Estado, mas um processo desigual de perda para alguns e ganho para outros.

Logo, a teia de poder soberano não pode ter sido formada antes das relações entre Estados, pois a própria soberania sempre envolveu uma interdependência, vez que sempre se tratou do reconhecimento da soberania de um Estado por outro. 0 que se pretendeu, com essa análise da soberania, foi modificar a tendência das ciências sociais (especialmente do direito) de pensar os fenômenos sociais, políticos e econômicos somente dentro das estruturas do Estado-nação.

\section{CONCLUSÃO}

Diante do conflito entre o poder institucionalizado nas dimensões do Estado moderno, fruto de estruturas sociais sólidas, e uma sociedade que progride para a liquidez de fluxos e relações, é mais do que relevante considerar as crises pelas quais passa o Estado nessa adaptação necessária, bem como os motivos de tais problemas. Somente é possível delinear soluções para as eventuais crises, portanto, com a compreensão do que é e de como se comporta o Estado frente à atual configuração das estruturas sociais.

Adotou-se, aqui, a abordagem histórica da continuidade ou descontinuidade parcial das estruturas estatais de Saskia Sassen, segundo a qual 
o Estado moderno representa a assemblage dos elementos território, autoridade e direito. Com esta ferramenta de análise, torna-se possível a visualização de construção-desconstrução pelas quais passa a entidade estudada diante das novas formas de organização do sistema em que o próprio Estado está inserido. Desse modo, compreende-se a crise como um dos processos pelos quais passa o Estado para reorganizar seus objetivos estruturantes.

Entre os motivos das crises comentadas, destaca-se o fenômeno da desterritorialização e a perda da soberania estatal como alguns dos principais elementos apontados em relação à desestruturação do Estado, causada pelos movimentos que compõem o fenômeno da globalização.

Conforme foi visto, a globalização é um fenômeno complexo, de múltiplas vias, ou seja, composto por microprocessos que, algumas vezes, resultam na desnacionalização das estruturas do Estado e, em outras, proporcionam o seu fortalecimento. É por essa razão que Saskia Sassen (2006, p. 1) afirma que "a transformação que estamos vivenciando é uma arquitetura complexa com muitos elementos distintos, dos quais somente alguns podem ser facilmente codificados como globalização"28.

Um dos problemas, como apontado, é que a maior parte das análises sobre globalização tende a colocar o Estado no papel de vítima de um processo de desconstrução das suas estruturas, o que não é, necessariamente, verdade. Ainda, costumam dar ênfase aos movimentos obviamente globalizadores, sem atentar para as sutilezas dos microprocessos de construção e desconstrução do espaço nacional, estes muito mais sutis, caóticos e frequentemente multifacetados.

Nesse cenário, Saskia Sassen aponta e diverge das estruturas tradicionais associadas frequentemente ao processo de globalização que, para ela, não significa o fim do Estado. Aqui é possível que se volte à sua teoria de continuidade ou descontinuidade parcial para chegar à conclusão de que o que vivenciamos como crise é, na verdade, uma transição de readaptação do Estado às configurações diametralmente distintas do fenômeno globalizacional.

A desterritorialização do Estado atribui-lhe uma característica que não corresponde aos fundamentos tradicionais de sua existência, como a vinculação a um território em que seja possível o controle e a coerção 
dos cidadãos que a ele se submetem. A liquidez dos fluxos informacionais que caracterizam o sistema atual, entretanto, é definida pelo exato oposto: o desprendimento das limitações territoriais. Adaptar-se a isso gera o referido enfraquecimento do Estado e o distanciamento dos seus objetivos fundantes.

Contudo, o enfraquecimento do Estado não significa o seu fim, pois, conforme também constatado, não existe contradição entre a sua crise e a sua permanência. Isso porque, no contexto da multiplicação dos poderes selvagens (Ferrajoli, 2011), a existência de Estados fracos é interessante para a expansão dos poderes globais, que transpassam as estruturas estatais tradicionais.

A discussão de perda ou adaptação da soberania estatal refere-se, ainda, à limitação do Estado frente aos problemas que, além de nacionais, pertencem a uma cadeia global e que, portanto, precisam de influência equiparável para serem contornados, característica incabível à entidade estatal, territorializada. Apesar dessa percepção, entende-se que o que está acontecendo é, na verdade, a constatação de que a soberania não é absoluta, possibilitando que a mesma saia da esfera estatal para legitimar outros espaços de atuação das relações, agora, globais.

Sob essa ótica, o surgimento das novas tecnologias da informação, inquestionavelmente, coloca em xeque a ideia de efetividade do atual modelo de Estado, uma vez que tais tecnologias desestabilizam as tradicionais hierarquias associadas à modernidade sólida. Embora continuem existindo em diversos contextos da vida social - afinal, o surgimento de novos problemas não acaba com os antigos -, essas estruturas de poder da Era Moderna possuem baixa capacidade de controlar os fluxos globais de dados do mundo contemporâneo.

Por outro lado, é equivocado fazer afirmações no sentido de que as tecnologias da informação, especialmente a Internet, estão imunes a qualquer tipo de controle (Sassen, 2006, p. 331), porque muitos Estados, especialmente os tecnologicamente mais desenvolvidos, participam, ativamente, no desenho da arquitetura de hardware e software da tecnologia. Além disso, uma grande fonte de regulamentação dos meios digitais são os interesses privados, especialmente os das grandes empresas de tec- 
nologia, que modelam, conforme seus interesses, os avanços e padrões técnicos.

Ainda assim, as categorias existentes na teoria do Estado - bem como do direito internacional - são incapazes de lidar com o surgimento de poderes não estatais com capacidade de ação transnacional. Por isso, este trabalho delimitou-se a analisar como ocorrem tais transformações nos pressupostos do Estado, sobretudo, em virtude dos influxos da globalização e da desnacionalização de suas capacidades específicas, especialmente diante do contexto daquilo que se convencionou chamar de modernidade líquida (Bauman, 2001).

As limitações espaço-temporais do Estado não parecem ser capazes de lidar com os problemas que afetam o mundo, cada vez mais globalizado e "líquido", situação que já pode ser vista no direito ambiental ${ }^{29} \mathrm{e}$, para objetivos deste estudo, no alcance dos fluxos de informações que permite uma conexão a nível global.

Por fim, a conclusão da análise aqui realizada não se trata de excluir o papel das estruturas públicas estatais na proteção dos interesses nacionais, mas de ressaltar a necessidade de adição de novas respostas para problemas igualmente novos. Isso porque estes últimos não podem ser pensados somente a partir do direito estatal caso se deseje garantir a efetividade da soberania de que se devem valer as instituições jurídicas regulamentadoras de direitos. 0 poder, ao contrário, deve existir, assim como as redes da nova sociedade, além dos muros institucionais.

\section{NOTAS}

1 A crise do Estado é o principal tema de estudo da Rede de Pesquisa Estado \& Constituição, composta por diversas universidades do mundo inteiro e coordenada pelo Prof. Dr. Jose Luis Bolzan de Morais. Maiores detalhes sobre a rede e os seus eventos podem ser visualizados no seu site. Disponível em: <http://www.repec.com.br>. Acesso em: 26 mar. 2016.

2 No original: "[...] is a set of institutional forms of governance maintaining an administrative monopoly over a territory with demarcated boundaries (borders), its rule being sanctioned by law and direct control of the means of internal and external violence."

3 No original: "The combination of a large community (nation) and territorial, politica form (state), creating a cultural-political entity, now the most widespread 'survival unit' across thr world."

4 Para uma análise percuciente da formação da esfera pública burguesa, ver (HABERMAS, 2003).

5 Segundo Bobbio (2007, p. 69), o debate sobre a continuidade ou descontinuide depende de critérios de oportunidade, não de verdade. 
6 No original: "[...] the complex and abstract notion of the legitimate authority of the national territorial sovereign does not represent a radical innovation of the postfeudal order".

7 No original: "medieval capabilities".

8 No original: "[...] a capability can be regeared toward new logics and get lodged into novel path dependencies. I see this happening in the current global age when state capabilities historically constructed for the pursuit of national goals today get reoriented toward global projects".

9 Nesse sentido, Bauman (1999, p. 75, grifos do autor) afirma que "a corrida para criar novas e cada vez mais fracas entidades territoriais "politicamente independentes" não vai contra a natureza das tendências econômicas globalizantes; a fragmentação política não é uma "trava na roda" da "sociedade mundial" emergente, unida pela livre circulação de informação. Ao contrário, parece haver uma íntima afinidade, mútuo condicionamento e reforço entre a "globalização" de todos os aspectos da economia e a renovada ênfase no "princípio territorial" [...] Pode-se dizer que todos têm interesses adquiridos nos "Estados fracos" - isto é, nos Estados que são fracos, mas mesmo assim continuam sendo Estados".

10 Zygmunt Bauman (1999) adota a tese de Paul Virílio sobre o "fim da geografia", visto que considera que as distâncias físicas não importam mais. Para o autor, a geografia encontra-se em uma situação-limite em virtude da compressão do globo viabilizada pela globalização. Embora não seja possível concordar com a totalidade do argumento, há de se concordar com Bauman quando ele afirma que surgiram novas entidades extraterritoriais, ou seja, para as quais o espaço não constitui uma restrição, sendo elas independentes em relação às unidades territorialmente confinadas de poder político. Como resultado, o Estado acaba sendo enfraquecido nesse contexto da globalização em virtude do surgimento de poderes capazes de se mover dentro e através dos territórios.

11 No original: "Local transformation is as much a part of globalization as the lateral extension of social connections across time and space".

12 Seguindo na mesma esteira, inclusive apoiado no conceito de globalização de David Held, Vicente de Paulo Barretto, com base na matriz teórica de cunho kantiano, faz uma percuciente análise das sociedade, cidadania e direito cosmopolitas (BARRETTO, 2013, p. 234 e ss.).

13 Na física, a velocidade de escape corresponde à energia necessária para um objeto escapar de um campo gravitacional.

14 No original: “[...] does illuminate important transformations going on in the spatial organization of power - the changing nature of communication, the diffusion and speed-up of technical change, the spread of capitalist economic development, and so on - even if its understanding of these matters sometimes exaggerates their scale and impact".

15 No original: "These processes take place deep inside territories and institutional domains that have largely been constructed in national terms in much of the world. What makes these processes part of globalization even though they are localized in national, indeed subnational, settings is that they are oriented towards global agendas and systems. They are multisited, transboundary networks and formations which can include normative orders; they connect subnational or 'national' processes, institutions and actors, but not necessarily through the formal interstate system. Examples are cross-border networks of activists engaged in specific localized struggles with an explicit or implicit global agenda, for example, human rights and environmental organizations; particular aspects of the work of states, for example, certain monetary and fiscal policies critical for the constitution of global markets now being implemented in a growing number of countries; the use of international human rights instruments in national courts; and non cosmopolitan forms of global politics that remain deeply attached to or focused on localized issues and struggles."

16 No original: "[...] the 'rule of law' is a capability that was critical to the strengthening of national state authority to institute national economic protectionism. But today it is also critical to the global economy in order to open national economies. It is sufficiently developed that it can operate in a context of national protected economies and also become a key building block for the success of neoliberal deregulation and privatization - to some extent features that are the opposite of protectionism. But it can do so only by getting relodged in a new organizing logic."

17 No original: "The new is messier, more conditioned, and with older lineages than the grand new global institutions and globalizing capabilities suggest". 
18 Em 20 de maio de 2013, o analista de sistemas ligado à National Security Agency (NSA), Edward Joseph Snowden, divulgou informações sobre uma complexa estrutura de coleta e análise massiva de dados mundiais a partir de bases de monitoramento instaladas em todo o mundo pela NSA em parcerias com governos e empresas de tecnologia como o Google, com o objetivo de obter dados referentes a todas as comunicações humanas e entre máquinas ou a partir delas. Dentre os alvos de espionagem, o Brasil foi um dos países observados pela agência de inteligência.

19 Vide infra, item 1.

20 No original: "Getting relodged into denationalizing and global organizing logics not only reorients these capabilities toward objectives other than those to which they were oriented, it also recostitutes the construction of the public and the private, and of the boundaries between these domains".

21 No original: "[...] the current phase of globalization consists at least partly of global systems evolving out of the capabilities that constituted territorial sovereign states and the interstate system. In other words, the territorial sovereign state, with its territorial fixity and exclusivity, represents a set of capabilities that eventually enable the formation or evolution of particular global systems-itself a partial condition-that require neither territoriality nor exclusivity."

22 No original: "It is a decentered and deterritorializing apparatus of rule that progressively incorporates the entire global realm within its open, expanding frontiers. Empire manages hybrid identities, flexible hierarchies and plural exchanges through modulating networks of command."

23 No original: "A novel order is not an invention ab novo, and it does not necessarily announce itself as new, as radical strangeness - like science fiction or a futuristic account."

24 No original: "l. Las transmisiones de datos informatizados, las emisiones de radio, la detección remota por satélite y las llamadas por teléfonos celulares no se detienen en los puestos aduaneros. Además dichas comunicaciones suceden: (a) a velocidades que hacen difícil que la vigilancia de los Estados las detecte de antemano; y (b) en cantidades que ningún Estado puede seguir, incluso aunque aumente sus capacidades. 2. Los medios electrónicos de masas también suponen una merma del dominio del Estado sobre la construcción de la lengua y la educación. 3. Un Estado no puede ejercer autoridad plena sobre asociaciones transfronterizas y empresas globales. 4. Un Estado no puede asegurar con éxito el dominio supremo y exclusivo sobre los flujos, financieros globales que atraviesan su jurisdicción. 5. Las condiciones ecológicas mundiales, como la disminución de la capa de ozono y de la diversidad biológica también han mermado los requisitos materiales de la soberania."

25 Em sentido contrário, veja-se a notícia sobre o formulário do sistema de busca Bing, da Microsoft, para solicitação de retirada dos resultados das pesquisas, obedecendo à sentença do Tribunal Europeu relativa ao direito ao esquecimento. Embora a ordem tenha partido do Tribunal, quem, no final das contas, decide sobre essa "ponderação" de direitos humanos é a equipe da Microsoft. Segundo o formulário, "ces informations nous aideront à évaluer l'équilibre entre votre intérêt individuel à la protection de votre vie privée, et l'intérêt public consistant à protéger la libre expression et le libre accès à l'information [...] Microsoft ne garantit pas qu'un résultat de recherche spécifique sera bloqué". Ver a matéria no jornal Le Monde. Disponível em: $<\underline{\mathrm{http}}$ ://surveillance. es/20>. Acesso em: 27 mar. 2016.

26 Sobre o caso, observar item 3, nota de fim 11.

27 No original: "[...] deep structural shifts underlying surface continuities and, alternatively, deep structural continuities underlying surface discontinuities."

28 No original: "The transformation we are living through is a complex architecture with many distinct working elements, only some of which can easily be coded as globalization."

29 A dificuldade do Estado-nação em lidar com fenômenos "descolados" do espaço não se restringe à tecnologia da informação. Nesse sentido, veja-se o exemplo da questão ambiental, analisada por Jose Luis Bolzan de Morais (2011, p. 75), Leonel Severo Rocha (2009, p. 40) e Wilson Engelmann (2011, p. 315). 


\section{REFERÊNCIAS}

BARRETTO, V. D. P. 0 fetiche dos direitos humanos e outros temas. 2. ed. Porto Alegre: Livraria do advogado, 2013. 372 p. Kindle Edition.

BAUMAN, Z. Globalização: as consequências humanas. Tradução de Macus Penchel. Rio de Janeiro: Jorge Zahar, 1999. 148 p.

BAUMAN, Z. Modernidade líquida. Tradução de Plínio Dentzien. Rio de Janeiro: Zahar, 2001. 258 p.

BOBBIO, N. Estado, governo e sociedade: para uma teoria geral da política. Tradução de Marco Aurélio Nogueira. 14 ed. Rio de Janeiro: Paz e Terra, 2007. $173 \mathrm{p}$.

BOLZAN DE MORAIS, J. L. As crises do Estado contemporâneo. In: VENTURA, D. D. F. L. América Latina: Cidadania, Desenvolvimento e Estado. Porto Alegre: Livraria do Advogado, 1996. p. 37-50.

BOLZAN DE MORAIS, J. L. As crises do estado e da constituição e a transformação espacial dos direitos humanos. 2. ed. Porto Alegre: Livraria do Advogado, 2011. 143 p.

BOLZAN DE MORAIS, J. L.; STRECK, L. L. Ciência política e teoria do estado. 7. ed. Porto Alegre: Livraria do Advogado, 2007. 211 p.

CASTELLS, M. The power of identity: The information age - economy, society and culture. 2. ed. Chichester: Wiley-Blackwell, 2010a. v. 2. 538 p.

CASTELLS, M. The rise of the network society: The information age economy, society and culture. 2. ed. Chichester: Willey-Blackwell, 2010b. v. 1. $597 \mathrm{p}$.

CHEVALLIER, J. 0 Estado pós-moderno. Tradução de Marçal Justen Filho. Belo Horizonte: Fórum, 2009. 309 p.

FERRAJOLI, L. Poderes salvajes: la crisis de la democracia constitucional. Tradução de Perfecto Andrés Ibáñez. Madrid: Trotta, 2011. 109 p. 
FERRAJOLI, L. Processo desconstituinte. In: GALLO, D.; IPPOLITO, F. Salviano la constituzione. Taranto: Chimienti, 2005. p. 93-110.

GIDDENS, A. Essential Concepts in Sociology. Cambridge: Polity Press, 2014. 6059 p. Kindle Edition.

GIDDENS, A. Sociology. 6. ed. Cambridge: Polity, 2009. 1194 p.

GIDDENS, A. The Globalizing of Modernity. In: HELD, D.; MCGREW, A. The Global Transformations Reader: An Introduction to the Globalizing Debate. 2. ed. Cambridge: Polity, 2003. p. 60-66.

GIDDENS, A. The Nation-State and Violence. Cambridge: Polity Press, v. 2, 1985. 399 p.

HARBERMAS, J. A constelação pós-nacional: ensaios políticos. Tradução de Márcio Seligmann-Silva. São Paulo: Littera Mundi, 2001. 220 p.

HARDT, M.; NEGRI, A. Globalization as Empire. In: HELD, D.; MCGREW, A. The Global Transformations Reader: An Introduction to the Globalizing Debate. 2. ed. Cambridge: Polity, 2003. p. 116-66.

HELD, D. Democracy and the Global Order: From the Modern State to Cosmopolitan Governance. Stanford: Stanford University Press, 1995. 324 p.

HELD, D.; MCGREW, A. The Great Globalization Debate: An Introduction. In: HELD, D.; MCGREW, A. The Global Transformations Reader: An Introduction to the Globalizing Debate. 2. ed. Cambridge: Polity, 2003. p. 1-50.

MANN, M. Has a Globalization Ended the Rise and Rise of the Nation-State? In: HELD, D.; MCGREW, A. The Global Transformations Reader: An Introduction to the Globalizing Debate. 2. ed. Cambridge: Polity, 2003. p. 135-146.

MORIN, E. Cultura e barbárie européias. Tradução de Ana Paula de Viveiros. Lisboa: Instituto Piaget, 2005. 75 p.

SASSEN, S. Losing control? Sovereignty in an Age of Globalization. New York: Columbia University Press, 1996. Não paginado. 
SASSEN, S. Sociology of globalization. New York: W. W. Nortton \& Company, 2007. 308 p.

SASSEN, S. Territory, authority, rights. Woodstock: Princeton University Press, 2006. 493 p.

SORENSEN, G. La transformación del Estado: más allá del mito del repliegue. Tradução de Ramón Cotarelo. Valência: Tirant lo blanch, 2010. 229 p.

Recebido em: 12-11-2018

Aprovado em: 18-12-2018

\section{Elias Jacob de Menezes Neto}

Mestre e Doutor em Direito Público pela Universidade do Vale do Rio dos Sinos. Professor adjunto do curso de Direito da Universidade Federal do Rio Grande do Norte, campus de Caicó/RN. Coordenador do Laboratório de Governança Pública da UFRN.

E-mail: eliasjacob@ceres.ufrn.br 
